March 2018

\title{
Traditional canister-based open waste management system versus closed system: Hazardous exposure prevention and operating theatre staff satisfaction
}

M Horn

Kareena Private Hospital, Caringbah, NSW, Australia, et65@acorn.org.au

N Patel

KMßT Asia and Pacific, et66@acorn.org.au

M MacLellan

KMњT Asia and Pacific, et67@acorn.org.au

N Millard

Stryker Australia, et68@acorn.org.au

Follow this and additional works at: http://demo.acorn.bepress.com/jpr

Part of the Health Services Administration Commons, Health Services Research Commons, Perioperative, Operating Room and Surgical Nursing Commons, and the Surgery Commons

\section{Recommended Citation}

Horn, M; Patel, N; MacLellan, M; and Millard, N (2018) "Traditional canister-based open waste management system versus closed system: Hazardous exposure prevention and operating theatre staff satisfaction," Journal of Perioperative Nursing: Vol. 28 : Iss. 1 , Article 2 .

Available at: http://demo.acorn.bepress.com/jpr/vol28/iss1/2 


\title{
Traditional canister-based open waste management system versus closed system: hazardous exposure prevention and operating theatre staff satisfaction
}

\author{
M Horn • RN, CNS* \\ Kareena Private Hospital, Caringbah, NSW, Australia \\ * Martlie Horn was employed at Prince of Wales Hospital, Randwick, NSW at the time the study was performed.
}

\author{
N Patel • BEng DIS \\ KM\&T Asia and Pacific \\ M MacLellan • MBA \\ KM\&T Asia and Pacific
}

N Millard • BBioMed (Hons), MMedSci

Stryker Australia

Corresponding author

Martlie Horn, CNS Orthopaedic In Charge/Floor supervisor, Theatre, Kareena Private Hospital, 86 Kareena Road, Caringbah, NSW 2229, Australia

Tel:02 97170278 Fax:02 95251606 Email: HornM@ramsayhealth.com.au

\section{Abstract}

Introduction: Exposure to blood and body fluids is a major concern to health care professionals working in operating rooms (ORs). Thus, it is essential that hospitals use fluid waste management systems that minimise risk to staff, while maximising efficiency.

Method: The current study compared the utility of a 'closed' system with a traditional canister-based 'open' system in the OR in a private hospital setting.

Results: A total of 30 arthroscopy, urology, and orthopaedic cases were observed. The closed system was used in five, four, and six cases, respectively and the open system was used in nine, two, and four cases, respectively. The average number of opportunities for staff to be exposed to hazardous fluids were fewer for the closed system when compared to the open during arthroscopy and urology procedures. The open system required nearly 3.5 times as much staff time for set-up, maintenance during procedures, and post-procedure disposal of waste. Theatre staff expressed greater satisfaction with the closed system than with the open.

Conclusion: In conclusion, compared with the open system, the closed system offers a less hazardous and more efficient method of disposing of fluid waste generated in the OR.

\section{Keywords}

Waste management, hospital, operating room.

\section{Introduction}

The goal of every health care facility is to dispose of fluid medical waste from the operating room (OR) efficiently and cost-effectively while protecting health care professionals (HCPs) from exposure to pathogenic bacteria and viruses. Yet, accidental exposure of the skin or mucosa to body fluids remains a major occupational hazard for $\mathrm{HCPs}^{1}$.

OR staff are particularly at risk of being exposed to blood-borne pathogens and body fluids during surgical procedures ${ }^{2,3}$. In one sixyear retrospective study conducted in a 430-bed Australian teaching hospital, Bi and colleagues found that close to half $(48.1 \%)$ of all blood and body fluid exposures occurred in the emergency, perioperative, and surgical divisions ${ }^{2}$.
In the OR, blood and fluids present in and around open wounds and flushed from wound sites pose the risk of mucocutaneous exposure. In the study by $\mathrm{Bi}$ and colleagues, more than half (57\%) of the 337 mucocutaneous exposures documented involved splashes of blood and blood products. HCPs in the emergency and perioperative divisions had the highest rate of mucocutaneous exposure ${ }^{2}$.

Two types of management systems are used to collect waste fluid in the OR setting - traditional 'open' systems and the more recent innovation of 'closed' systems. Risk of exposure with open systems occurs when HCPs need to change canisters during a surgical procedure; when disconnecting canisters from the suction port at the end of each case; and when disposing of the canisters in contaminated waste bags. 
To decrease opportunities for HCP exposure to hazardous fluid waste, manufacturers have developed closed systems where fluids are collected and transported directly from the operating theatre to disposal. Stryker's Neptune 2 Waste Management System is a totally closed, all-in-one unit that collects and disposes of surgical fluid waste with minimal operator assistance. In most instances, the only intervention required by staff is manifold connection and disconnection, all but eliminating the risk of fluids spilling or splashing.

To quantify the incidence of exposure of OR staff to hazardous fluid waste and the ease-of-use and burden on staff of each system, a study was conducted comparing the Neptune 2 closed system with a traditional open canister-based system.

\section{Method}

In November 2012, 30 operations were observed over seven days during a three-week period at a Sydney metropolitan private hospital, NSW, Australia, specialising in cardiovascular, endovascular, urological, and orthopaedic surgery. At the time, in their 10 ORs, the hospital had three Neptune 2 units in use as well as several open canister systems. Observers were representatives of $\mathrm{KM} \& \mathrm{~T}$, a global health care consulting firm. Their role was to objectively measure the amount of time taken to change canisters and observe and record any fluid spills or exposures.

Cases, performed by six surgeons, were observed in six OR suites. Procedures selected for observation were thought to generally involve high volumes of fluid waste. These were mainly arthroscopy, orthopaedic, and urology procedures. The goal was to observe a total of 30 cases, 15 of which involved the use of an open-canister system and the remainder of which involved the closed system. Every attempt was made to observe cases where the same surgeon used both systems on similar procedures.

Observers mapped out a process flow indicating all steps required to set up, maintain, and clean each system (Figure 1).

For each procedure the following observations were recorded on an observation chart:

- Name of surgeon

- Type of surgery.

- Equipment used (that is, open- or -closed canister).

- Distance covered (measured by tape measure).

- Total time taken to perform each of the steps involved in using either system (measured by stopwatch).

- Total number of contact events (any episode in which a HCP came into contact with a piece of equipment that may have been contaminated, such as when changing a canister).

- Duration of contact event.

. Total amount of waste fluid generated.

In addition, all OR staff were asked to complete a survey rating their satisfaction with each system including ease of use, safety in terms of spills/splashes and heavy lifting/manual handling, time taken to set up
Table 1: HCP satisfaction survey*

\begin{tabular}{cccccc}
\hline Criteria & Low & & & & High \\
\hline 1 & 2 & 3 & 4 & 5 \\
\hline
\end{tabular}

\section{Ease of use}

\section{Safety in terms of spills/splashes}

3. Safety in terms of heavy lifting/manual handling

4. Time taken to set up equipment

5. Time taken to maintain equipment during surgery

6. Time taken to clean/dispose of fluid waste

7. Reliability

What is your role/responsibility within the $O R$ ?

Which system do you prefer to use in the OR (circle one)? Canister or Neptune 2

Why?

How could the canister system be improved?

How could the Neptune 2 system be improved?

* Respondents were asked to rate each system on the following criteria (where 1 is the lowest score and 5 is the highest)

equipment, time taken to maintain equipment during surgery, time taken to clean up/dispose of fluid waste, and reliability. Respondents used a Likert scale where one was the lowest rating and five was the highest. Respondents were also asked to indicate which system they preferred and why, as well as offer suggestions for improving either system (Table 1 ).

\section{Purpose}

The primary objectives of the study were to:

- Quantify the opportunity for hazardous exposure to HCPs by counting the number of contact events when using the closed system versus an open system.

Quantify the incidence of manual handling when using the closed versus open system.

The secondary objectives included:

Amount of time typically spent setting up, maintaining, and cleaning each system.

Amount of time and distance involved to transport and dispose of fluid waste.

Volume of waste generated for disposal in landfills.

Ascertain level of staff satisfaction with both systems.

\section{Results}

Data was collected from 15 procedures where the open system had been used (arthroscopy $n=9$; urology $n=2$; orthopaedic $n=4$ ) and 15 cases where the closed system had been used (arthroscopy $n=5$; urology $n=4$; orthopaedic $n=6$ ). 


\section{A. Traditional canister system}

\section{Pre-theatre set-up}

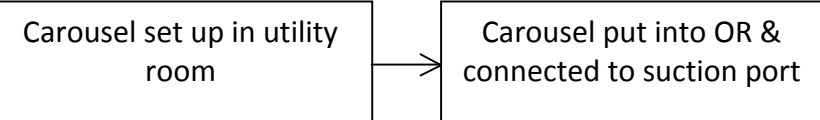

In theatre

Attach Y bridge + suction lines

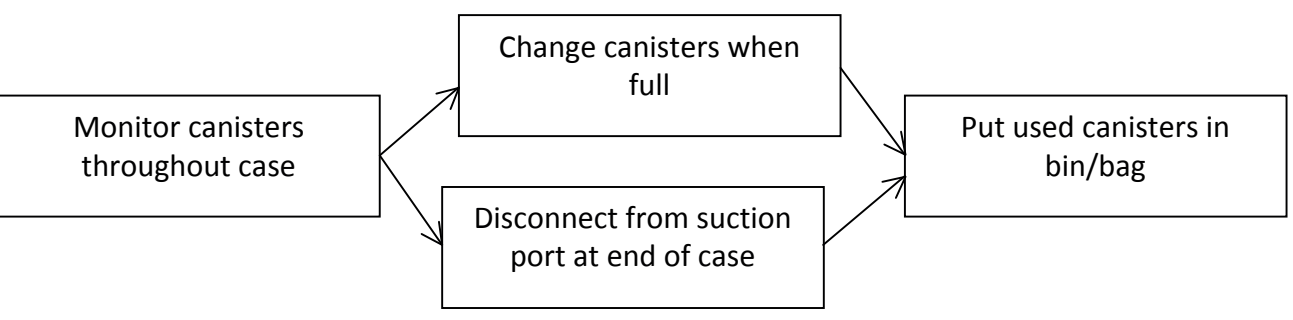

\section{Post-theatre}

Remove bin/bag to utility

\section{A. Closed system}

Load bags to trolley (6 per trolley)
Wheel trolley to dumpster
Load bags into dumpster

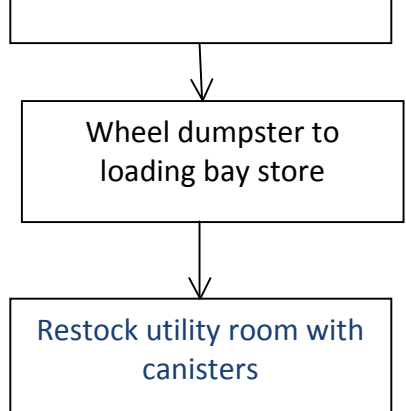

\section{Pre-theatre set-up}

Wheel to OR \&

connect closed

system to power

socket

\section{In theatre}

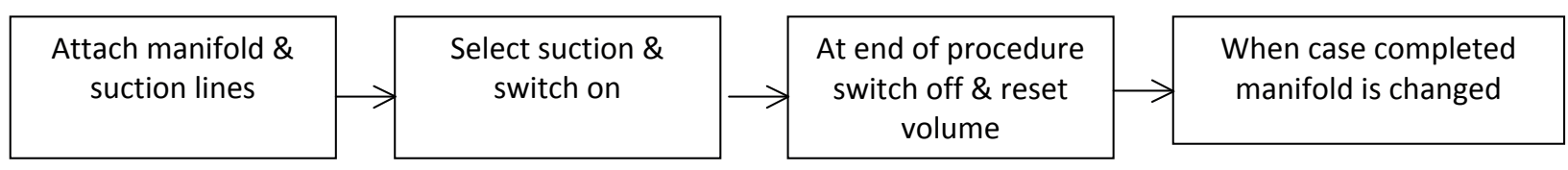

\section{Post-theatre}

\begin{tabular}{|c|}
$\begin{array}{c}\text { Wheel to docking } \\
\text { station when full or } \\
\text { not required for } \\
\text { other cases }\end{array}$ \\
othesh \\
cycle
\end{tabular}


Table 2: Observations during surgery

\begin{tabular}{|c|c|c|}
\hline \multirow{2}{*}{$\begin{array}{l}\text { Procedure type } \\
\text { Arthroscopy }\end{array}$} & \multicolumn{2}{|c|}{ System } \\
\hline & $\begin{array}{l}\text { Closed } \\
(n=5)\end{array}$ & $\begin{array}{l}\text { Open } \\
(n=9)\end{array}$ \\
\hline Total surgery time (mins) & 266 & 511 \\
\hline Average contact events per case & 2.8 & 4.7 \\
\hline $\begin{array}{l}\text { Average contact event time per } \\
\text { case (mins, secs) }\end{array}$ & 3,24 & 8,24 \\
\hline Urology & $\begin{array}{l}\text { Closed } \\
(n=4)\end{array}$ & $\begin{array}{l}\text { Open } \\
(n=2)\end{array}$ \\
\hline Total surgery time (mins) & 96 & 115 \\
\hline Average contact events per case & 1.5 & 2 \\
\hline $\begin{array}{l}\text { Average contact event time per } \\
\text { case (mins, secs) }\end{array}$ & 1,18 & 2,48 \\
\hline Orthopaedic & $\begin{array}{l}\text { Closed } \\
(n=6)\end{array}$ & $\begin{array}{l}\text { Open } \\
(n=4)\end{array}$ \\
\hline Total surgery time (mins) & 263 & 224 \\
\hline Average contact events per case & 2 & 1.5 \\
\hline $\begin{array}{l}\text { Average contact event time per } \\
\text { case (mins, secs) }\end{array}$ & 2,30 & 11,48 \\
\hline
\end{tabular}

\section{Observations}

The typical capacity for each individual canister in an open-system is 2 litres compared with 24 litres for the canisters used in the Neptune 2 unit. The canister carousel used in the open-system was typically set up with 3 to 4 canisters for each procedure (a total holding capacity of 6-8 L). The basic process for change of canisters during cases was: disconnect suction hosing when full, connect to new canister, plug full canister using attached cap and either remove full canister to bin or to the floor and replace with new unused canister or leave in situ until end of procedure and remove at final clean-up when carousel is returned to ready condition. All used canisters (full or partly full) were removed to the yellow contaminated-waste bags along with the used drapes and any other potentially contaminated items.

As the Neptune 2 unit is self-contained, at the end of a list, or when full, it was wheeled to the docking station and emptied and washed automatically at the push of a button. At the end of a case the manifold was removed along with the suction tubing and disposed of in the yellow contaminated-waste bags.

In arthroscopy and urology cases, compared with the open system, there were fewer opportunities for hazardous exposure with the closed system. In these cases, the average number of contact events per case was $40 \%$ and $25 \%$ less for the closed system versus the canister system, respectively. In all procedure types the average contact event time per case was lower for the closed system (Table 2).

No hazardous exposure events were observed when the closed system was in use. Three events were observed when the open system was in use (splash onto clothing whilst the circulating nurse was changing canister, spill onto the floor when staff member was modifying suction piping route, and a second spill onto the floor when a waste collection bucket was moved to the utility room).
Observation of the process flow revealed that total time for all steps involved in set-up, maintenance, waste disposal, and cleaning of the closed system was 92 seconds with a total distance of 102 metres. For the open system, total time taken was 320 seconds and a total distance of 114 metres (Table 3).

Manual handling was observed to be minimal with the closed system. With the open system, full or partially full canisters were observed to be handled or transported at least five times in the disposal process. Each canister weighed $2 \mathrm{~kg}$ when full.

Waste stored in the closed system was suctioned into the hospital's effluent system. After each case, the only items requiring separate disposal were the manifold and attached tubing (weighing approximately $150 \mathrm{~g}$ in total). With the open system, the canisters were disposed of in contaminated-waste bags and eventually transferred to landfill. The weight of each full canister and associated tubing weighed considerably more than the material disposed in landfill for each closed system case. Although total fluid collected for traditional canister cases was greater than that for Neptune 2 cases ( $49 \mathrm{~L}$ vs $39.5 \mathrm{~L}$ ), if equal amounts of fluid had been collected, that is, $39.5 \mathrm{~L}$ for both, weight to landfill for canisters would be approximately $40 \mathrm{~kg}$ compared with approximately $2.4 \mathrm{~kg}$ for Neptune 2 .

Table 3: Time and distance involved in process flow

\begin{tabular}{|c|c|c|}
\hline \multicolumn{3}{|l|}{ Open system } \\
\hline Process flow & $\begin{array}{c}\text { Time } \\
\text { (seconds) }\end{array}$ & $\begin{array}{l}\text { Distance } \\
\text { (metres) }\end{array}$ \\
\hline Carousel set up in utility & 51 & 0 \\
\hline Move carousel to OR and connect to suction ports & 7 & 6 \\
\hline Attach $Y$ bridge and suction lines & 2 & 0 \\
\hline Change canisters during the case* & 27 & 0 \\
\hline Disconnect at end of case & 27 & 0 \\
\hline Dispose of used canisters to bin/bag & 3 & 3 \\
\hline Remove bin/bag to utility & 3 & 5 \\
\hline Load bags to trolley & 5 & 0 \\
\hline Wheel trolley to dumpster & 70 & 50 \\
\hline Load bags into dumpster & 15 & 0 \\
\hline Wheel dumpster to loading bay store & 110 & 50 \\
\hline Total & 320 & 114 \\
\hline \multicolumn{3}{|l|}{ Closed system } \\
\hline Step & $\begin{array}{c}\text { Time } \\
\text { (seconds) }\end{array}$ & $\begin{array}{l}\text { Distance } \\
\text { (metres) }\end{array}$ \\
\hline Wheel to OR and connect to power socket & 50 & 50 \\
\hline $\begin{array}{l}\text { Attach manifold and suction lines/select suction } \\
\text { setting }\end{array}$ & 3 & 0 \\
\hline Switch off and reset & 2 & 2 \\
\hline Disconnect manifold with suction lines & 2 & 0 \\
\hline Wheel to docking station & 30 & 50 \\
\hline Dock, select wash cycle & 2 & 0 \\
\hline Restock manifolds & 3 & 0 \\
\hline Total & 92 & 102 \\
\hline
\end{tabular}

* This time is applicable when all $6 \times 2$ litre canisters have been used 


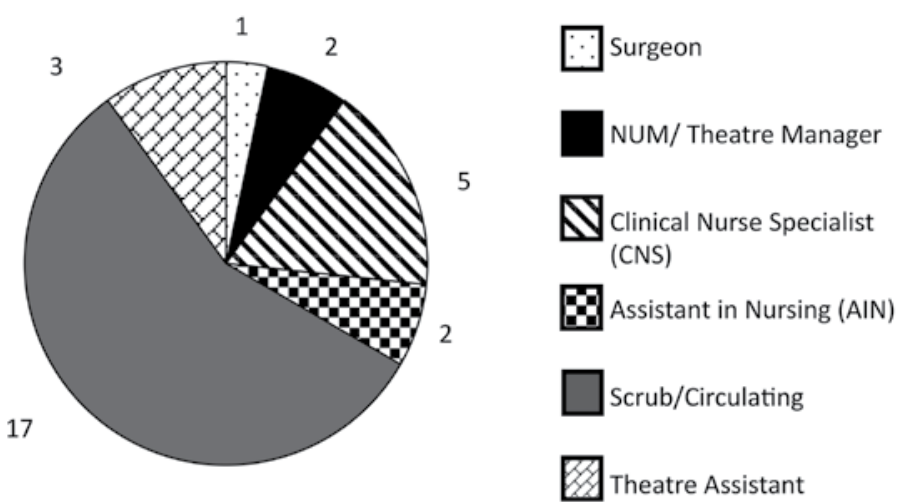

Figure 2: Survey respondents $(n=30)$

\section{HCP survey results}

A total of 30 HCPs completed the survey designed to evaluate theatre staff satisfaction with each system. The majority of respondents were scrub or circulating nurses (Figure 2).

The overall satisfaction score for the closed system was $90 \%$ compared with $60 \%$ for the open system. The closed system was rated higher on usability, safety, manual handling, set-up time, maintenance time, changeover time, and reliability (Figure 3). A total of 28 respondents preferred the closed system, one preferred the open system, and one indicated no preference.

In general, comments made by respondents reinforced their satisfaction rating. Other specific survey comments suggested that the closed system was preferable for high fluid volume procedures. Also, the fact that up to eight suction tubes could be added to the closed system without loss of suction was cited as a benefit.

\section{Discussion}

The results from this study would indicate that, compared with a traditional canister-based open system, there is less risk of exposure to blood and body fluids when a closed system is used in the OR. As the closed-system can hold 24 litres of fluid, it does not routinely require emptying after each case. On the other hand, the open system requires set-up, maintenance, and disposal activities for each case,

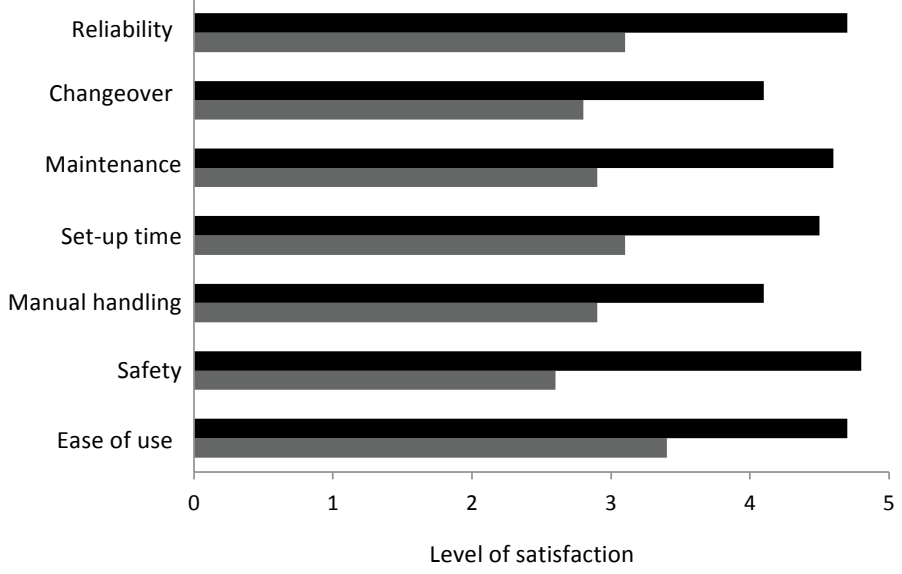

- Closed system Open system

Figure 3: Survey responses ( $0=$ low level of satisfaction; $5=$ high level of satisfaction) regardless of how much or how little fluid is collected, thus increasing the risk of exposure to hazardous waste.

The results suggest that the closed system is more efficient than the open system. Set-up, handling and maintenance time is 3.5 times longer with the open system than that required with the closed system. At the study hospital, based on an average of 450 cases per week (arthroscopy, urology, and orthopaedic), it is estimated the open system would require an additional 25 hours of theatre staff's time.

The environmental impact of the closed system is considerably less than that of the open system as the volume and weight of waste requiring landfill disposal is minimal for each case. The open system may require up to six canisters for each case, all of which require landfill disposal.

Theatre staff surveyed expressed greater satisfaction with the closed system on all parameters queried. They found it quick and easy to set up and clean and that it required less attention than the open system during a procedure and between cases. Because there is less manual handling and lifting involved with the closed system, it has the potential to reduce the incidence of manual handling injuries.

\section{Conclusion}

OR staff are particularly at risk of being exposed to blood-borne pathogens and body fluids during surgical procedures. This fluid is most often captured using an open system where the fluid is suctioned and collected into canisters. HCPs can be exposed to this fluid when changing and disposing of canisters. Risk of exposure to blood and bodily fluids falls when fluid is collected into a closed system.

When compared with a traditional canister-based open waste management system, a closed system reduces the number of opportunities for theatre staff to be exposed to hazardous fluid waste during surgical procedures. It offers superior ease-of-use and has less environmental impact. In general, theatre staff agree that the closed system offers a less hazardous and more efficient method of disposing of fluid waste generated in the OR. Studies comparing the costs associated with each system will be valuable.

\section{Acknowledgement}

The authors would like to thank Jo Stratmoen for editorial support.

\section{Disclosures}

KM\&T was employed by Stryker to design and conduct the study.

Natascha Millard is an employee of Stryker involved in the management of the study.

\section{References}

1. Mohammadi N, Allami A, \& Malek Mohamadi R (2011). Percutaneous exposure incidents in nurses: Knowledge, practice and exposure to hepatitis B infection: Percutaneous exposure incidents in nurses. Hepatitis Monthly, No. 11, pp. 186-90.

2. Bi P, Tully PJ, Pearce S \& Hiller JE (2006). Occupational blood and body fluid exposure in an Australian teaching hospital. Epidemiology \& Infection, Vol. 134, pp. 465-71.

3. Cutter J \& Jordan S (2013). The systems approach to error reduction: factors influencing inoculation injury reporting in the operating theatre. Journal of Nursing Management, Vol. 21, pp. 989-1000. 